\title{
Education for arthritis patients: a community pharmacy based pilot project
}

\author{
Received (first version): 16-Jan-2009 Accepted: 2-Apr-2009
}

\begin{abstract}
$^{\star}$
There are different kinds of arthritis, widely spread among the population, that make them a clinical problem with social, psychological and economic burden. Different education programs have been developed in order to improve patients' disease management, medication compliance and from there patients' quality of life.

Objective: To develop and implement a community pharmacy-based educational program for patients with arthritis. Improvements in pain, medication compliance, decrease in general practitioner's visits and hospitalizations are expected.

Methods: Prospective, randomized, controlled trial. The sample consisted of 43 individuals, with different stages of arthritis (aged 15 - 71), attending pharmacies - intervention group; and 43 individuals - control group. A 4-month education was conducted on the following topics: what causes arthritis and what are the factors that can intensify it; pain management and physical activities; selfmanagement and prevention; pharmacotherapy and possible adverse drug reactions. Patient's healthrelated quality of life was assessed in the beginning and at the end of the survey.

Results: Parameters assessed during the four stages of the program were: frequency of severe pain, frequency of general practitioner's visits, frequency of urgent medical aid calls, compliance with therapy, satisfaction with pharmacy services. Improvement in patients' health-related quality of life was observed and also: decrease in the severity of patients' pain, decrease in the physician's visits, and increase in satisfaction overall care.

Conclusions: Positive results from the educational approach in pharmacy conditions were demonstrated. These consequences have a potential to increase arthritis patient's quality of life.
\end{abstract}

Keywords: Arthritis. Community Pharmacy Services. Patient Education as Topic. Bulgaria.

\author{
EDUCACIÓN PARA PACIENTES CON \\ ARTRITIS: PROYECTO PILOTO EN \\ FARMACIA COMUNITARIA
}

\section{RESUMEN}

Hay diferentes tipos de artritis, ampliamente distribuidas en la población, que las convierten en un problema clínico con carga social, psicológica y económica. Se han desarrollado varios programas educativos para mejorar el manejo de la enfermedad por los pacientes y con ello la calidad de vida de los pacientes.

Objetivo: Desarrollar e implantar un programa educativo desde farmacias comunitarias para pacientes con artritis. Se esperan mejoras en el dolor, cumplimiento de la medicación, disminución de las visitas a médico general, y hospitalizaciones. Métodos: Ensayo controlado, aleatorizado prospectivo. La muestra consistió en 43 individuos con diferentes estadios de artritis (edad 15-71 años) que visitaron farmacias (grupo intervención); y 43 individuos (grupo control). Se realizó una educación de 4 meses sobre los temas: que causa la artritis y cuáles son los factores que pueden intensificarla; manejo del dolor y actividades físicas; autogestión y prevención; farmacoterapia y posibles efectos adversos. Se evaluó la calidad de vida de los pacientes al principio y al final de la investigación.

Resultados: Los parámetros evaluados durante las 4 fases del programa fueron: frecuencia de dolor severo, frecuencia de visitas a medico general, frecuencia de llamadas a servicios de urgencia, cumplimiento de la medicación, satisfacción con los servicios farmacéuticos. Se observó una mejoría en la calidad de vida relacionada con la salud de los pacientes, así como disminució0n en la severidad del dolor, disminución de las visitas a médicos, y aumento de la satisfacción general con la atención. Conclusiones: Se demostraron resultados positivos del abordaje educativo en farmacia. Estas consecuencias tienen el impacto potencial de aumentar la calidad de vida de los pacientes con artritis.

Palabras clave: Artritis. Servicios de farmacias comunitarias. Educación de pacientes como tema. Bulgaria.

\section{INTRODUCTION}

Arthritis is inflammation of one or more joints, which results in pain, swelling, stiffness, and limited
Valentina B. PETKOVA. PhD. Associate Professor.
Department of Social Pharmacy, Faculty of Pharmacy Medical University-Sofia (Bulgaria). 
movement. Pain is the most common symptom and is associated with bad functional outcomes and poor quality of life. ${ }^{1}$ It can be differentiated as articular pain (mechanical or inflammatory involvement of the joint) or periarticular pain (emanating for instance from the bursa, tendon or ligament). Arthritis causes half of all disabilities among older persons. ${ }^{2-4}$ It limits the major activities - working, housekeeping, sports, etc. As a consequence, arthritis limits the independence of affected persons and contributes to social isolation, depression and generally - decreased quality of life. The management of arthritis is complex and relies on a combination of pharmacological and nonpharmacological approaches, including drug treatment, physiotherapy, occupational therapy, podiatry, physical exercises, weight control and lifestyle adjustment. For most of the patients, management of arthritis relies mainly on optimization of pharmacotherapy. Unfortunately there are many reports of extra medication, because of the pain. This misuse often leads to intoxication and occurrence of adverse drug reactions, hospitalizations, general practitioner's (GP) visits, and additional treatment and from there - to increase in the treatment cost. ${ }^{5-8}$

Based on the available literature, the educational programmes for patients with arthritis are personalized for each patient and depend on the type and severeness of the disease, drug treatment, age and other socio-physiological factors. These programmes have given people with arthritis the strategies and tools necessary to make daily decisions to cope with the disease. ${ }^{9}$ Education of patients with arthritis can lead to better pain management and from there to improvement of patients' quality of life. ${ }^{10,11}$ The pharmacist's contribution to patient care through education and monitoring, and through assessing and optimizing the drug therapy can lead in general to better disease management. ${ }^{12}$

\section{METHODS}

The goal of this article was to develop and implement education program for arthritis patients at community pharmacy conditions and to evaluate its influence on the patients' quality of life. The study design was a prospective and randomized study with a control group. Patients covering the criteria for rheumatoid arthritis and osteoarthritis ${ }^{13}$ were invited to participate in the study. They were registered as arthritis patients at St. Ivan Rilski University Multiple Profile Hospital for Active Treatment, Sofia, Bulgaria. The inclusion criteria were diagnosis of arthritis, age 18 years or older, and fluency in Bulgarian. Exclusion criteria were: presence of other significant chronic disease (e.g., carcinoma), presence of any condition that would hinder completion of questionnaires (e.g., poor eyesight or literacy). 90 patients were included, diagnosed between 1996 and 2006. 45 of them were assigned to the educational group and 45 to the control group. The assignment was based on the principle of random numbers through custom random number generator. The divided into 2 groups patients did not have the option to switch study groups. All the participants were informed on the objectives of the study and have signed a basic consent form. Patients' condition and disease severity was taken down by their personal medical records. The information was confirmed by a rheumatologist from the St. Ivan Rilski University Multiple Profile Hospital for Active Treatment, Sofia.

The pharmacies were selected through the list of private community pharmacies, located in Sofia, Bulgaria, provided by the Bulgarian Ministry of Health (1134 private pharmacies). The 20th pharmacies with the highest number of arthritis patients were selected. The education was performed by the author and by 5 pre-graduating students that have passed their exam in Pharmaceutical care. Additional training was given to them to be prepared for the role of educators. There was a 3-day intensive training course provided by a rheumatologist, pharmacists and a therapist. The training course included a brief review of the disease, pain management, risks, exercise, joint protection and ended with a roleplaying of various situations that can happen in the pharmacy.

Patient diaries were made. They included information about the patient's disease complications, severity of pain based on a 10degree Numerical rating scale $(0$ - for no pain and 10 -for worst possible pain) and prescribed drugs. If there were any problems encountered with treatment they were also included in the diary. Patients were kindly asked not to change their pharmacy during the experiment.

The control group was treated as usual at the pharmacy, with no additional information, while the educational group attended educational sessions for a period of 4 months. The educational program continued 4 months (01 February-31 May 2008). It was designed and adapted to the local conditions of the Bulgarian community pharmacy. It covered the following topics:

- information about the disease itself, factors that can lead to complications, how to differentiate the different kinds of arthritis, risk factors for development of arthritis;

- the proper application of "heat" and "cold" therapy;

- the importance of physical training and joint protection;

- pain management, drug medication and ADRs during treatment.

All the educational materials were developed by the authors. They were based on the information provided by the National Health Insurance Fund for treatment of arthritis diseases (clinical paths for physical treatment and rehabilitation of arthritis diseases and musculoskeletal system) and by the Arthritis Foundation. The educational leaflets were prepared in the form of a self-study program that includes information on one of the above mentioned topics. After every educational session they were 
given to the patients. During the program there were applied:

- $4 \times 45=180$ information leaflets on the different education sessions;

- 90 patient's health diaries;

- 90 Brief pain Inventory questionnaires;

- 90 Satisfaction with services questionnaires.

In the beginning of the second, third and forth sessions there were provided interviews on the previous topics in order to be assessed the level of the newly achieved knowledge and to be clarified any doubt or illegibility $(n=135)$. There was a checklist and the interviewer took notes. This type of interview is impersonal and seeks to reveal the real level of knowledge achieved. The following parameters were assessed at baseline and every month:

- patient's arthritis self-monitoring. Patients were asked how often they have experienced pain the severity and duration of the pain crisis, how often they have called to urgent medical aid and how often they forgot to take their prescribed drugs. Patients were also asked about their visits to the doctor, concerning arthritis. The UMA calls frequency and GP visits were verified through their medical records.

- patients' subjective opinions of the patient's health-related quality of life were assessed through adapted disease-specific instrument Brief Pain Inventory (Copyright 1991 Charles S. Cleeland) that was translated into Bulgarian using conventional back translation procedure. The Brief Pain Inventory uses 0 to 10 numeric rating scales for item rating because of its simplicity, lack of ambiguity and seemed the best to use for cross-linguistic pain measurement. Using numeric 0 to 10 scales, with 0 being "no interference" and 10 being "interferes completely," the Brief Pain Inventory asks for ratings of the degree to which pain interferes with mood, walking and other physical activity, work, social activity, relations with others, and sleep. The Brief Pain Inventory has demonstrated respectable test-retest item correlations (reliability). Evidence for the validity of the Brief Pain Inventory comes from several studies using the instrument with cancer patients and patients with other diseases who had pain. The Brief Pain Inventory is sensitive to differences in pain characteristics associated with different diseases. It has several applications, including studies of the epidemiology of cancer pain, the routine clinical assessment of pain, efforts to assure the quality of pain management, and the conduct of clinical trials examining the effectiveness of cancer pain treatments. It was applied in the beginning and during the final meeting with the patient.

- patient's satisfaction with the services provided by educators in community pharmacy conditions was assessed through the satisfaction with services questionnaire, translated into Bulgarian using conventional back translation procedure. It was provided in the end of the education process. The results from it show the patient's satisfaction with the education they have received in the pharmacy. (Table 1$).{ }^{11}$

The data obtained from quality-of-life instrument and the changes between the baseline and the 4 months period for the various measures were compared within and between the two groups of patients using $t$ tests, and the Mann-Whitney $U$ test (between-group analysis), as appropriate. A p value below 0.05 was considered statistically significant. Statistics were performed by using SPSS/version 14.0.

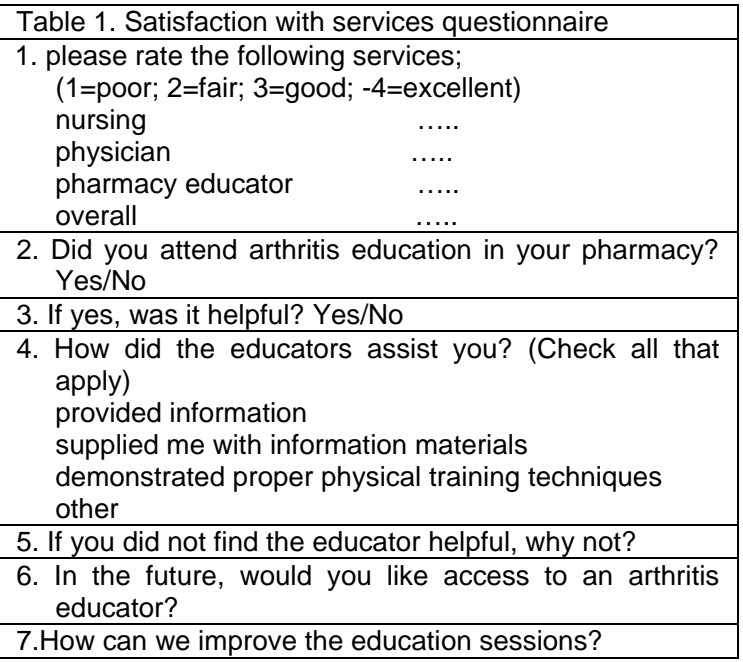

\section{RESULTS}

Ninety patients were eligible to participate in the study: 45 in the intervention group (Group 1) and 45 in the control group (Group 2). But after the first session 2 patients from Group 1 and 2 patients from group 2 ceased the program, because of lack of time. So finally, 86 patients finished the study. The results represent the data about those patients that have finished the study. Table 2 gives demographic information about the two groups.

Statistically there is no significant difference between the number of men and women in the intervention and control group ( $p>0.05)$. The control group is younger than the control group. All the patients had health insurance coverage and were educated. The secondary and higher education predominate in both groups. Married and widowed patients prevail in the both groups. The duration of the arthritis since diagnosis is comparatively equal in both groups.

The results comparison table 3 represents the influence of the education on the studied parameters: pain management, arthritis selfmonitoring, ADRs due to improper medication and quality of services provided. Four months after the initial encounter with the pharmacist, patients who received arthritis education obtained greater overall knowledge about their disease.

It is clear that there are some differences between the two groups at baseline: the frequencies of urgent medical aid calls are lower in the control group then in the intervention group. 


\begin{tabular}{|l|c|c|}
\hline Table 2. Main characteristics of the population sample. \\
\hline Demographics & Intervention Group $(\mathrm{n}=43)$ & $\begin{array}{c}\text { Control Group } \\
(\mathrm{n}=43)\end{array}$ \\
\hline Age & $45.74 \pm 2.72$ & $44.58 \pm 2.611$ \\
\hline Sex & $29(67.4 \%)$ & $25(58.1 \%)$ \\
Female & $14(32.6 \%)$ & $18(41.9 \%)$ \\
Male & 2.07 & 1.38 \\
\hline Female/male ratio & & \\
\hline Education (\%) & 16.3 & 9.3 \\
Basic & 34.9 & 46.5 \\
Secondary & 48.8 & 44.2 \\
High & & 4.7 \\
\hline Marital status (\%) & 16.3 & 46.5 \\
Single & 32.6 & 39.5 \\
Married & 42.0 & 9.3 \\
Widowed & 9.1 & $45.33 \pm 5.921$ \\
Separated/divorced & $52.56 \pm 6.209$ & \\
\hline Duration of disease since diagnosis (months) & & \\
\hline Data are \% and means SD. & & \\
\hline
\end{tabular}

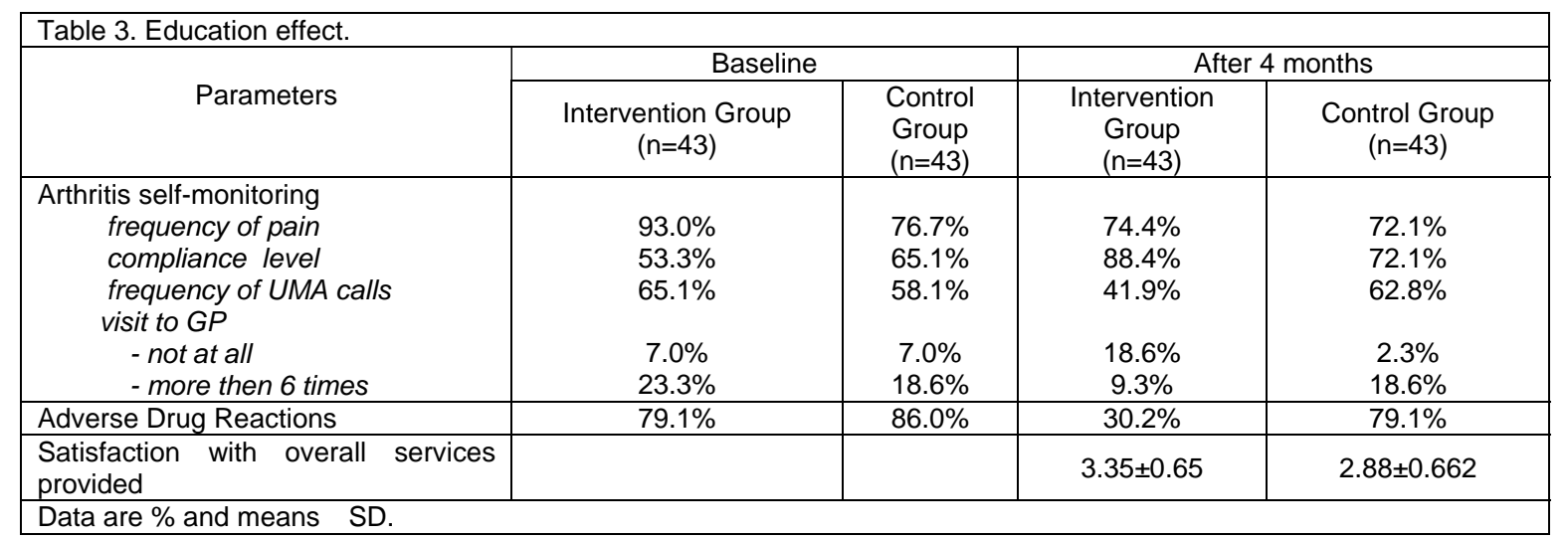

\begin{tabular}{|l|c|c|c|c|}
\hline \multicolumn{2}{|l|}{ Table 4 Arthritis interference in patients'daily routine } \\
\hline & \multicolumn{2}{|c|}{ Baseline } & \multicolumn{2}{c|}{ After 4 months } \\
\hline & $\begin{array}{c}\text { Intervention } \\
\text { Group }\end{array}$ & Control Group & $\begin{array}{c}\text { Intervention } \\
\text { Group }\end{array}$ & Control Group \\
\hline PAIN INTERFERENCE WITH: & & & & \\
\hline General activity & $7.63(1.235)$ & $7.67(1.229)$ & $7.47(1.316)$ & $7.63(1.134)$ \\
\hline Mood & $7.16(1.851)$ & $7.14(1.612)$ & $6.95(1.690)$ & $7.09(1.630)$ \\
\hline Walking ability & $7.93(1.370)$ & $8.00(1.272)$ & $7.72(1.368)$ & $7.88(1.258)$ \\
\hline Normal work & $6.81(2.228)$ & $6.51(2.120)$ & $6.67(2.212)$ & $6.56(1.980)$ \\
\hline Relation with other people & $4.26(2.391)$ & $4.00(2.370)$ & $4.14(2.210)$ & $3.74(2.183)$ \\
\hline Sleep & $7.98(1.752)$ & $8.09(1.231)$ & $7.79(1.390)$ & $8.02(1,282)$ \\
\hline Enjoyment of life & $6.95(1.812)$ & $6.93(1.737)$ & $6.58(1.803)$ & $7.09(1.90)$ \\
\hline Data are \% and means (Standard Deviation). & & & \\
\hline
\end{tabular}

During the study patient's self-monitoring was provided that included patient's report about the existence, duration and severity of pain; level of compliance with medication prescribed; availability of urgent medical aid calls; ADRs and compliance with the drug treatment.

Patients reported frequency of pain due to their disease. In the beginning $93.0 \%$ of the intervention group and $76.7 \%$ of the control group declared severe pain due to their disease. After the education there was a significant improvement for the patients in the intervention group than in the control group (74.4\% vs $72.1 \%)$. ( $p=0.001$; chi-square test).

It appears that for the 43 patients in the intervention group who completed the study, the level of compliance with the prescribed medication at 4 months $(88.4 \%)$ was significantly higher than at baseline $(53.5 \%), \quad(p<0.0001$; paired $t$ test $)$, indicating that the education process has an influence on the proper drug treatment. The corresponding comparison for the control group showed that there is no significant change in the patients' results $65.1 \%$ in the beginning and $72.1 \%$ in the end ( $p=0.083$; paired t test).

Significant decrease in the frequency of urgent medical aid calls is observed in the intervention group. In the beginning of study $65.1 \%$ from the intervention group were calling for urgent medical aid comparing to $58.1 \%$ from the control group. After the education process there is decrease in the urgent medical aid calling rate in the intervention group. The patients reported that $41.9 \%$ needed 
their services. ( $p=0.001$; paired t test). The results in the control group did not show significant decrease in the rate of the calls $(58.1 \%$ vs. $62.8 \%)$. $(p=0.16$; paired t test)

The control group did not show any decrease in the frequency of GP visits - $18.6 \%$ have visited their physician more than 6 times before and after the project $(p=0.096$; paired t test)

While there is a significant decrease in the intervention group after the education - from $23.3 \%$ in the beginning to $9.3 \%$.

The number of those from the intervention group that did not need GP visit at all has increased to $18.6 \%$ after the education program. $(p=0.003$; paired $t$ test).

A significant decrease in the rate of ADRs reported was observed for the intervention group after the education. In the beginning of the project $79.1 \%$ have experienced any ADR, while in the end its rate has decreased to $30.2 \%$. $(p<0.001$; paired t test). There is no such a decrease for the control group $(86.0 \%$ vs. $79.1 \%)$ ( $p=0.083$; paired $t$ test). This result is very important because the influence of education on proper medication and avoidance of ADRs and other drug-related problems is obvious.

It was evident from the satisfaction survey that the whole education process was beneficial for the educated patients. The patients from the intervention group rated the overall services predominantly as "good" and "excellent" in comparison with the control group (3.35 SD=0.65 vs.2.88 $\mathrm{SD}=0.662, \mathrm{p}<0.001)$. It was interesting that about $10 \%(9.6 \%)$ of the control group answered that they would like a future access to an arthritis educator without attending the education sessions.

Analysis of the Brief Pain Inventory form showed no significant differences in the patients' quality of life because of the pain over the 4 months period in the seven described indexes: general activity; mood, walking ability, normal work, relation with other people, and enjoyment of life. They were assessed by an 11-grade scale (from 0 - "does not interfere" to 10- "completely interfere"). (Table 4)

When analyzing the data for each group over time, it is evident that significant improvements were observed for the intervention group for their "general activity":- $7.63 \mathrm{SD}=1.24$ before the education and $7.47 \mathrm{SD}=1.134$ after the education; "mood": 7.16 $\mathrm{SD}=1.85$ before the education and $6.95 \mathrm{SD}=1.69$ after the education; "relations with other people": 4.26 SD=2.39 before the education and 4.14 $\mathrm{SD}=2.21$ after the education; "enjoyment of life": $6.95 \mathrm{SD}=1.812$ before the education and 6.58 $\mathrm{SD}=1.803$ after the education. $(\mathrm{p}<0.05$; paired $\mathrm{t}$ test).

\section{DISCUSSION}

Arthritis, pain and the risk of exacerbations are major individual and public health and economic burden nowadays. The educating practice in arthritis management in community pharmacy conditions is a relatively new approach that integrates disease and drug management, patients' compliance assessment, prospective and retrospective drug utilization review, adverse drug reaction and toxicity screening and education of the patients. These services in everyday pharmacy practice show that they can provide a meaningful and useful addition to traditional rheumatology care by positively affecting the patient's knowledge and improving patient's satisfaction with healthcare services. ${ }^{11}$

The results from our study confirm the literature that education of arthritis patients can be effective and beneficial. It proves that pharmaceutical care provision is well received by the patients. ${ }^{11}$

Of course the study size is small and the length of the study is short, so the observed results can not lead to general conclusions about all the arthritis patients in Bulgaria. There are differences between the two groups at the start of the pilot project. But our aim as it was stated was to see is there any alteration in patients' results and the study shows some positive in the intervention group. The results show that the arthritis educator in the pharmacy can lead to positive impact on patient's disease management.

At the end of the study, the intervention group showed significant differences compared with the control group (education group baseline/after 4 month - control group baseline/after 4 month) with respect to: pain (93.0\%/74.4\% - 76.7\%-72.1\%); level of compliance with drug treatment (53.3\%/88.4\% - 65.1\%/72.1\%); decrease in the rate of urgent medical aid calls $(65.1 \% / 41.1 \%$ $58.1 \% / 62.8 \%)$, decrease in GP visits $(23.3 \% / 9.3 \%$ $18.6 \% / 18.6 \%)$.

Improvements in proper drug application were also observed. A significant decrease in the rate of the ADRs was shown - from $79.1 \%$ in the beginning to $30.2 \%$ in the end of the project.

Another aspect of this study was to determine whether the arthritis patient educator can improve patient's satisfaction with the clinic services. It was shown that the Bulgarian patients with educator were more satisfied with the overall care in comparison with the control group and they wanted additional continuous education in the pharmacy. ${ }^{11,12}$ The greater accessibility to the pharmacists and the lack of most of the psychological obstacles make the pharmacy a good place for extra education of the chronic disease patients and the pharmacists - an ideal resource for delivery of specific arthritis information. And also the patient educator in the Bulgarian pharmacy has the potential to improve patient's quality of life. ${ }^{13}$ The results confirm the need for constant patients' education for arthritis patients, as an essential part of their disease management in the pharmacy that will result in decrease of the exacerbations of the disease. The course was well-accepted both by patients and pharmacists. ${ }^{14-16}$

Such an approach has the potential to improve the quality of life of arthritis patients and it can be implemented in the daily pharmacy routine, after proper training of the pharmacists in order to cope 
with all the drug- and disease- related problems that can arise during the chronic disease management. The educated patients showed significant improvement in their "general activity", "mood", "relations with other people" and "enjoyment of life".

This study only outlines the directions in which the pharmaceutical care for arthritis patients can develop in Bulgaria and shows that the education in the Bulgarian pharmacy can lead not only to better disease management, but also to pharmacoeconomic benefits due to decrease of urgent medical aid calls, decrease of disease exacerbations and better drug management. ${ }^{11,13}$

\section{CONFLICT OF INTEREST}

None declared.

\section{References}

1. Sprangers MA, de Regt EB, Andries F, van Agt HM, Bijl RV, de Boer JB, Foets M, Hoeymans N, Jacobs AE, Kempen GI, Miedema HS, Tijhuis MA, de Haes HC. Which chronic conditions are associated with better or poorer quality of life? J Clin Epidemiol. 2000;53:895-907.

2. MacLean C. Quality Indicators for the Management of Osteoarthritis in Vulnerable Elders, Ann Intern Med. 2001;135:711-721.

3. Hughes SL, Dunlop D. The prevalence and impact of arthritis in older persons. Arthritis Care Res. 1995;8:257-264.

4. Hughes SL, Edelman P, Chang RW, Singer RH, Schuette P. The GERIAIMS. Reliability and validity of the arthritis impact measurement scales adapted for elderly respondents. Arthritis Rheum. 1991;34:856-865.

5. Chakraborty PP, Achar A. Spontaneous bleeding in a patient of rheumatoid arthritis: a complication after accidental overdose of methotrexate. J Assoc Physicians India. 2007;55:501.

6. Whittle $S$, Hughes R. Folate supplementation and methotrexate treatment in rheumatoid arthritis: a review, Rheumatology 2004;43:267-271.

7. Hoffmeister R. Methotrexate in rheumatoid arthritis. Arthritis Rheum. 1972;15:114.

8. Felson DT, Anderson JJ, Meenan RF. Use of short-term efficacy/toxicity tradeoffs to select second-line drugs in rheumatoid arthritis. A methaanalysis of published clinical trials. Arthritis Rheum. 1992;35:1117-25

9. Hirano P, Lauren D, Lorig K. Arthritis patient-education studies 1987-1991:a review of the literature. Patient Educ Couns 1994;24:9-54;

10. Daltroy L, Liang M. Arthritis Education: Opportunities and State of the Art, Health Educ Behav. 1993;20(1):3-16.

11. Branch VK, Lipsky K, Neiman T, Lipsky PE. Positive impact of an intervention by arthritis patient educators on knowledge and satisfaction of patients in a rheumatology practice. Arthritis Care and Research, 1999;12(6):370-375.

12. Gall EP, Meredith KE, Stillman PL, Rutala PJ, Gooden MA, Boyer JT, Riggs GE. The use of trained patient instructors for teaching and assessing rheumatologic care. Arthritis Rheum. 1984;27:557-563.

13. Hepler CD, Strand LM. Opportunities and responsibilities in pharmaceutical care. Am J Hosp Pharm. 1990;47:533-543.

14. Arnett FC, Edworthy SM, Bloch DA, McShane DJ, Fries JF, Cooper NS, Healey LA, Kaplan SR, Liang MH, Luthra HS, Medsger TA Jr, Mitchell DM, Neustadt DH, Pinals RS, Schaller JG, Sharp, JT, Wilder, RL, Hunder GG. The American Rheumatism Association 1987 revised criteria for the classification of rheumatoid arthritis. Arthritis Rheum 1988;31(3):315-324.

15. Lorig K, Lubeck D, Kraines RG, Seleznick M, Holman HR. Outcomes of self-help education for patients with arthritis. Arthritis and Rheumatism, 1985;28(6):680-685.

16. Lorig KR, Sobel DS, Ritter PL, Laurent D, Hobbs M. Effect of a Self-Management Program on Patients with Chronic Disease. Effective Clinical Practice, 2001;4(6):256-262. 